\title{
Synthesis and Characterization of Advanced Red Mud and MWCNTs Based EMI Shielding Material via Ceramic Processing
}

\author{
Sarika Verma*, Sudhir Sitaram Amritphale, Satyabrata Das \\ Council of Scientific and Industrial Research-Advanced Materials and Processes Research Institute, \\ Bhopal, India \\ Email: *drsarikaverma@hotmail.com
}

Received 20 February 2016; accepted 21 April 2016; published 27 April 2016

Copyright (C) 2016 by authors and Scientific Research Publishing Inc.

This work is licensed under the Creative Commons Attribution International License (CC BY). http://creativecommons.org/licenses/by/4.0/

c) (7) Open Access

\begin{abstract}
For the first time in the world advanced multi layered Red Mud and MWCNTs (ARMC) based EMI shielding material has been developed at CSIR-AMPRI, Bhopal. Red mud provides oxides of titanium and iron as precursor and the MWCNTs provides electrical conductivity characteristics necessary for making desired EMI shielding materials. The novel process involves unique designing of chemical compositions and mineralogical phases of red mud, MWCNTs together with appropriate additive and solvent which results in the simultaneous and synergistic chemical reactions among various constituents thereby forming tailored precursor powder. Further, the ceramic processing of tailored precursor powder in appropriate environment enables formation of advanced ARMC shielding material having a variety of ceramic phases with multi elemental compositions and multi layered crystal structures. The synthesized material was characterized by various techniques namely XRD, PL, FESEM, EDXA. The reflection loss $(R$. $L$.) of the sample was calculated based on the measured complex permittivity and permeability. The advanced ARMC material with thickness $\mathrm{t}=1.5 \mathrm{~mm}$ showed a minimum $R$. $L$. of $-35.5 \mathrm{Db}$ at $14.0 \mathrm{GHz}$ with a response band width of $1.8 \mathrm{GHz}$. Thus, the developed advanced ARMC material acts as a good EMI wave absorber.
\end{abstract}

\section{Keywords}

Red Mud, MWCNTs, EMI Shielding, Ceramic Processing, Multilayered Structure

\section{Introduction}

The present era is known as the era of radiation based technologies in all walk of the human race. Electromagnetic shielding is reducing the electromagnetic field by blocking it with materials having either conductive,

"Corresponding author.

How to cite this paper: Verma, S., Amritphale, S.S. and Das, S. (2016) Synthesis and Characterization of Advanced Red Mud and MWCNTs Based EMI Shielding Material via Ceramic Processing. Materials Sciences and Applications, 7, $192-201$.

http://dx.doi.org/10.4236/msa.2016.74019 
magnetic or both the characteristics. Shielding of Electromagnetic Interference (EMI) is in demand 1) due to the interference of wireless devices with digital devices, 2) due to the increasing sensitivity, and 3) due to increased importance of electronic devices [1]-[4]. Shielding is particularly required for power transformers containing vaults and other electronics that are related to electric power and telecommunications. The desired characteristics for obtaining advanced EMI shielding materials should preferably be a) light in weight, b) efficiently absorbing EM waves, c) possessing tunable absorption frequency, d) multifunctional, e) resistance to corrosion, f) flexible and g) having processing advantages [5]-[9].

Conventional EMI shielding materials are made using synthetic grade compounds of barium, titanium, iron and MWCNTs. The chemical reaction among these compounds leads to the formation of barium titanate, iron oxides in MWCNTs composite matrix. As reported by Tan et al. (2010) and Iyer et al. (1993), $\mathrm{BaTiO}_{3} \mathrm{and} \mathrm{TiO}_{2}$ posses high permittivity and dielectric constant, thereby improving the EMI shielding properties of the materials [10] [11]. Also as reported by Azadmanjiri et al. (2010) and Zhiguang Ding et al. (2015), the magnetic phases due to $\mathrm{Fe}_{2} \mathrm{O}$ show a marked increase in the absorption of EMI waves [12] [13].

In the present novel process red mud has been explored as a source of oxides of titanium and iron as precursor, MWCNTs provides desired electrical conductivity characteristics and barium hydroxide, being a source of barium for making advanced EMI shielding material. Red mud [14] is an aluminum industry waste which inherently contains varieties of elements namely iron, titanium, aluminum, silicon, calcium, magnesium and sodium etc and thus makes it a most suitable multi-component resource material for developing value added materials. Further these multi-elements in the red mud are present in the form of oxide, oxy-hydroxide and hydroxides, having low as well as high atomic numbers elements namely sodium, iron compounds respectively.

The unique structure and excellent properties of Carbon Nano Tubes (CNTs) (both single-walled and multiwalled (SWCNTs and MWCNTs)) like high aspect ratio, high conductivity, small diameter and mechanical strength have prompted its potential engineering applications, in the area of electronics, automotive and aerospace sectors. Further CNTs are use in electrostatic dissipation, electromagnetic interference (EMI) shielding, multilayer printed circuits and conductive coatings, etc. Several studies of using MWCNTs, as excellent option, for creating conductive composites for high-performance EMI shielding materials, have been reported [15]-[19].

So far no serious efforts have been made to explore the iron and titanium precursors of Red mud and MWCNTs together, for the development of novel advanced EMI shielding material. In order to obtain particle size of developed advanced ARMC shielding material ranging from micron to submicron up to nano size, cetyltrimethylammonium bromide has been used for reducing the particles size down to the nanometer range as well as stabilizing the formed particles [20] [21].

\section{Experimental}

\subsection{Material and Chemicals Required}

\subsubsection{Red Mud}

The Red Mud was collected from HINDALCO, Renukoot (U.P) for the study was analyzed in the laboratory for physico-chemical characteristics and the results are given in Table 1.

\subsubsection{Chemicals}

Multiwalled CNTs, Barium hydroxide, Sodium hydroxide, Cetyltrimethylammonium bromide (CTAB), ammonium nitrate were procured from Rankem and Ethylene glycol was procured from Merck. All the chemicals were used as such without further purification.

\subsubsection{Procedure}

The experimental work for the obtaining advanced ARMC shielding material has been divided into two parts in the following way.

1) Synthesis of tailored precursor powder

Synthesis of tailored precursor powder was done by together refluxing of $10 \mathrm{~g}$ of Red mud, $10 \mathrm{~g}$ barium hydroxide, $10 \mathrm{~g}$ MWCNTs, $15 \mathrm{~g}$ of cetyltrimethylammonium bromide and $20 \mathrm{~g}$ of sodium hydroxide in $400 \mathrm{ml}$ of ethylene glycol for the duration of $4 \mathrm{~h}$. The product was then precipitated with $30 \mathrm{ml}$ of aqueous ammonium nitrate solution ( $25 \mathrm{wt} \%$ ) and washed with the same solution to ensure complete precipitation. The precipitate so 
Table 1. Chemical analysis of red mud HINDALCO, Renukoot (U.P).

\begin{tabular}{ccc}
\hline Sr. No. & Constituents & $\%$ \\
\hline 1 & $\mathrm{LOI}$ & $8-10$ \\
2 & $\mathrm{Al}_{2} \mathrm{O}_{3}$ & $17-19$ \\
3 & $\mathrm{Fe}_{2} \mathrm{O}_{3}$ & $34-40$ \\
4 & $\mathrm{SiO}_{2}$ & $7-8$ \\
5 & $\mathrm{TiO}_{2}$ & $15-16$ \\
6 & $\mathrm{Na}_{2} \mathrm{O}$ & $5-6$ \\
7 & $\mathrm{CaO}$ & $1.8-5.0$ \\
8 & $\mathrm{P}_{2} \mathrm{O}_{5}$ & $0.31-0.47$ \\
9 & $\mathrm{~V}_{2} \mathrm{O}_{5}$ & 0.035 \\
\hline
\end{tabular}

obtained was dried in air oven at $110^{\circ} \mathrm{C}$ for $2 \mathrm{~h}$ and grayish black tailored precursor powder was obtained.

2) Ceramic processing of tailored precursor powder to obtain advanced ARMC shielding material

The resulting tailored precursor powder so obtained was converted in the form of rectangular coupon using warm press and was kept in furnace for sintering at $800^{\circ} \mathrm{C}$ for two hours in argon atmosphere i.e. ceramic processing of tailored precursor to obtain EMI shielding material.

The various steps involved in the developed novel process for synthesis of advanced ARMC shielding materials shown in Figure 1.

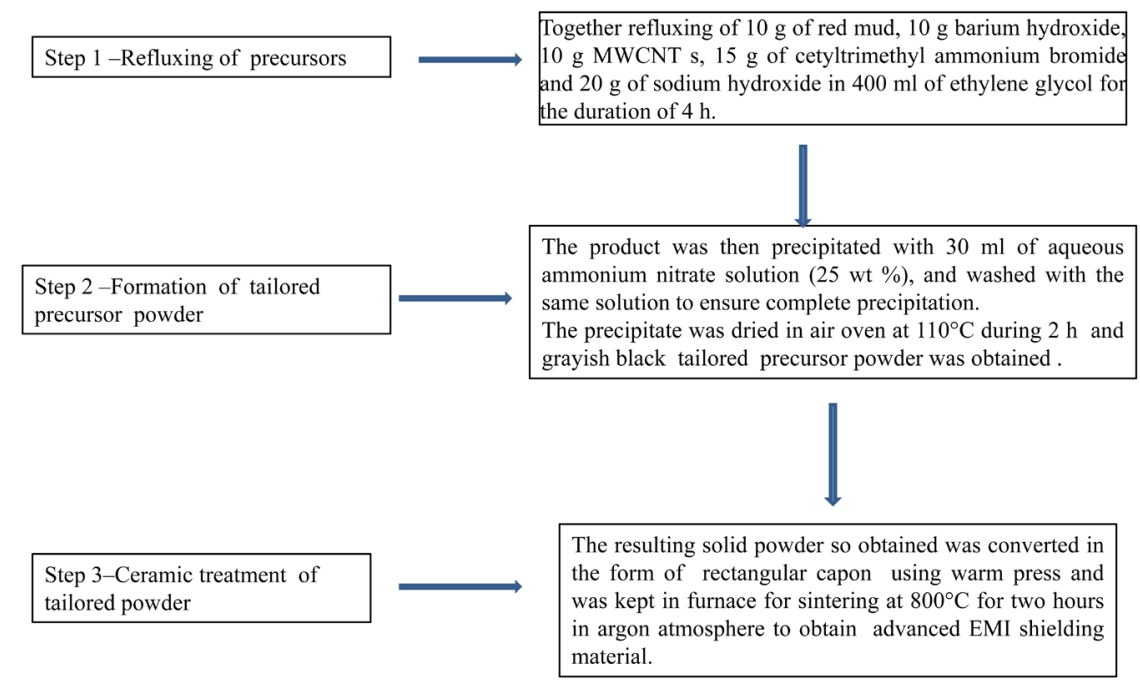

Figure 1. Flow sheet of advanced ARMC shielding material.

\subsection{Characterization}

$\mathrm{X}$-ray diffraction pattern was obtained on D8 advance X-ray diffractometer using $\mathrm{Cu} K_{\alpha}$ radiation to identify the various different phases. The X-ray diffraction intensity was recorded as a function of Bragg's $2 \theta$ in the angular range of $5^{\circ}-70^{\circ}$. The Photo luminescence measurement was recorded in Instrument Model: F-7000 FL Spectrophotometer with Serial Number: 2249-002 over the wavelength range from $300 \mathrm{~nm}$ to $700 \mathrm{~nm}$. Field Emission Scanning Electron Microscope (FESEM), model NOVA NANOSEM-430 of COMFEI and Energy-dispersive X-ray spectroscopy (EDXA), Model X-MAX of Oxford was used for determination of morphology and microstructure. Sample was sonicated for a period of 15 minutes in acetone before mounting for FESEM and EDXA. 


\section{Results and Discussion}

\subsection{X-Ray Diffraction Studies}

Identification of the various phases present in the synthesized advanced EMI shielding material formed during the reaction process was carried out by comparing the experimental inter planar spacing (d values) with those of the respective likely substances listed in the JCPDS standard X-ray diffraction (XRD) data files [22]. The X-ray diffraction spectrum (XRD) of the synthesized EMI material is shown in Figure 2 and the respective phases identified are given in Table 2 respectively.

In general the XRD patterns are composed of sharp peaks, indicating that the synthesized materials have good crystalline structure. The results of X-ray powder diffraction analysis of advanced material exhibited the presence of a diverse mineralogical phases and compounds namely barium iron titanium silicate (Bafertisite), barium aluminum silicate, iron titanium oxide, barium titanate, barium iron titanium oxide, barium aluminum oxide, magnetite, iron sulphide (troilite).

Crystallite size was obtained by using the Debye's Scherrer equation [23]:

$$
D=\frac{K}{\beta \cos (\theta)}
$$

where $K$ is the shape factor, $\lambda$ is the wavelength, $\beta$ is the line broadening at half the maximum intensity (FWHM) in radians and $\theta$ is the Bragg angle. The crystallite size was of the synthesized material was found to be in the range from $10-18 \mathrm{~nm}$.

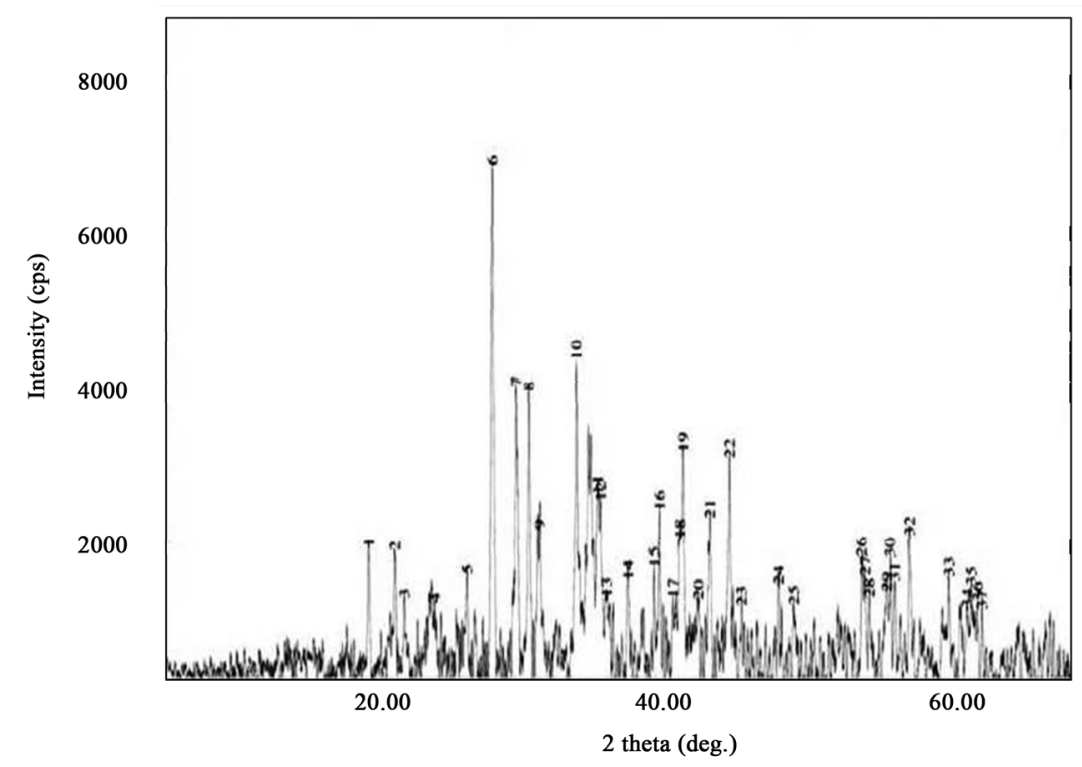

Figure 2. XRD pattern of advanced ARMC shielding material.

Table 2. Phases present in advanced ARMC shielding material.

\begin{tabular}{cccc}
\hline No. & Phase identified in material & JCPDS data (file number) & Crystal structure \\
\hline 1 & Barium iron titanium silicate (Bafertisite) & $14-541$ & Orthorhombic \\
2 & Barium aluminum silicate & $28-125$ & Hexagonal \\
3 & Iron titanium oxide (pseudorutile) & $13-270$ and $19-635$ & Tetragonal and hexagonal \\
4 & Barium titanate & $26-368$ & Hexagonal \\
5 & Barium iron titanium oxide & $28-121$ & Tetragonal to cubic \\
7 & Barium aluminum oxide & $19-629$ & Cubic \\
8 & Magnetite & $11-151$ & Hexagonal phases \\
\hline
\end{tabular}




\subsection{Photoluminescence}

The Photoluminescence spectra of the developed advanced ARMC shielding material is shown in Figure 3 and shows multiple peaks from 300 to $700 \mathrm{~nm}$ which confirms the presence of multi elemental and multi phased characteristics in the material. As reported by Ming-sheng Zhang et al. Strong photoluminescence spectrum centered at $696 \mathrm{~nm}$ was observed confirming the presence of barium titanate in the sample [24].

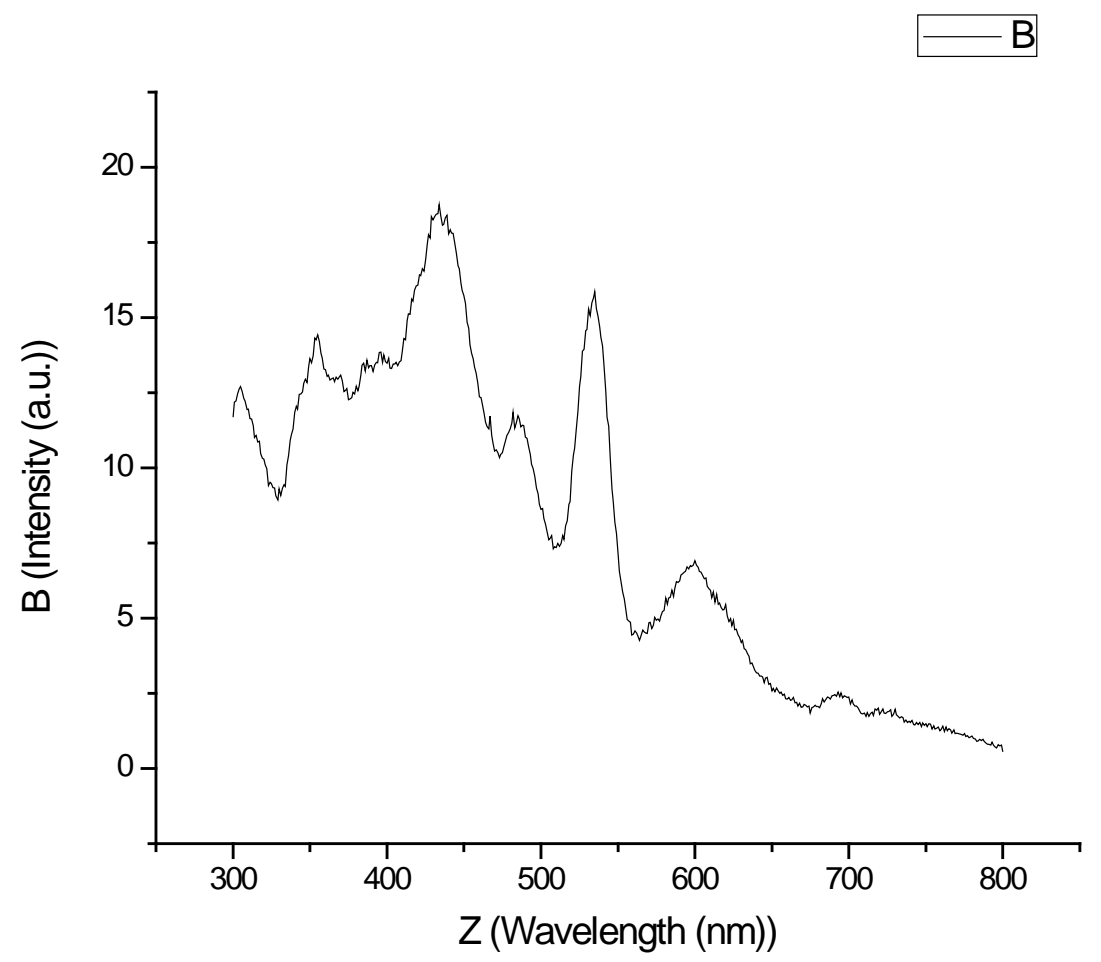

Figure 3. PL of advanced ARMC shielding material.

\subsection{FESEM and EDXA Analysis}

The particle size of synthesized advanced AFMC shielding material was examined using FESEM and EDXA respectively. Several particles were investigated to determine the particle size. FESEM image and EDXA spectra are shown in Figure 4 and Figure 5 respectively.
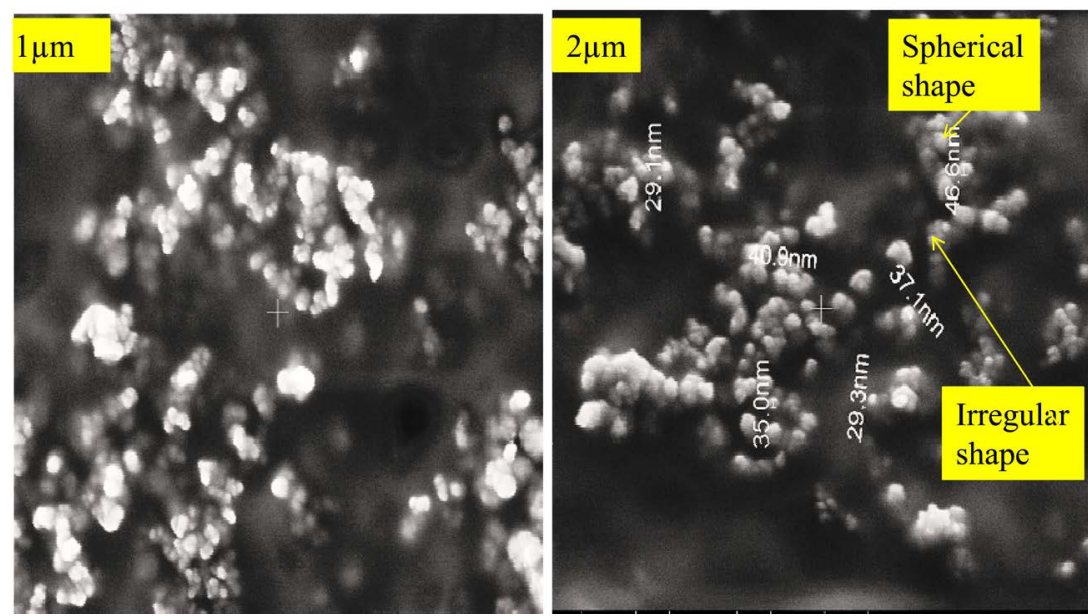

Figure 4. FESEM image of of advanced ARMC shielding material. 


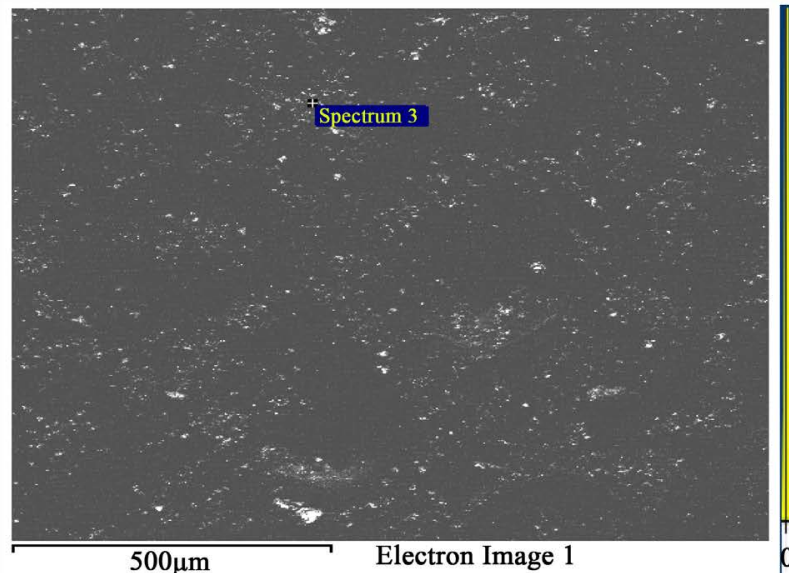

(a)

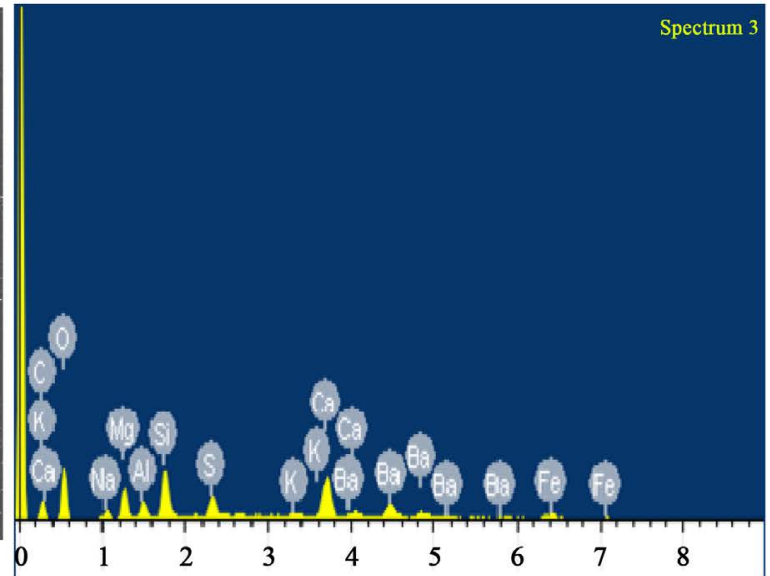

(b)

\begin{tabular}{|l|l|l|}
\hline Element & Weight\% & Atomic\% \\
\hline & & \\
\hline C K & 16.00 & 34.24 \\
\hline O K & 25.61 & 36.56 \\
\hline Na K & 1.61 & 1.60 \\
\hline Mg K & 2.42 & 4.15 \\
\hline Al K & 4.17 & 1.84 \\
\hline Si K & 6.12 & 5.79 \\
\hline Ti K & 4.12 & 2.94 \\
\hline K K & 0.99 & 0.58 \\
\hline Ca K & 8.97 & 6.82 \\
\hline Fe K & 10.16 & 2.52 \\
\hline Ba L & 17.83 & 2.97 \\
\hline & & \\
\hline Totals & 100.00 & \\
\hline
\end{tabular}

(c)

Figure 5. EDXA image of (a) synthesized of advanced ARMC shielding material. Selected area (b) EDXA outcomes (c) Elemental compositions (weight \% and atomic \%).

The FESEM image showed that the particles are of spherical as well as irregular in shape confirming the multiple types of chemical composition in synthesized material. The size varies in the range up to $29-46 \mathrm{~nm}$. The EDXA spectra revealed the predominance of multi elements like Barium, titanium, Aluminum, Iron, Carbon, Magnesium, Silicon, Sodium, Calcium and Oxygen.

\subsection{Permittivity and Permeability Study of Developed Advanced ARMC Shielding Material}

The study of permittivity $(\varepsilon)$ and permeability $(\mu)$ represents the dielectric and magnetic properties of the microwave absorber material. The real part of permittivity and permeability represents the storage of electric and magnetic energies respectively whereas the imaginary parts symbolize the loss and dissipation of both the energies.

The real and imaginary component of permeability for advanced ARMC shielding material with thickness, $\mathrm{t}=$ $1.0 \mathrm{~mm}$, over the range of $1-13 \mathrm{GHz}$ and is shown in Table 3. The table shows real and imaginary part of permeability for advanced ARMC shielding material in which the complex permeability of the sample increases with the increase in frequency till $12 \mathrm{GHz}$, after which it decreases. This can be due to natural resonance or eddy current loss. It is well known fact that when any conducting material was put in an alternating magnetic field, a close induced current will be produced inside the material, which dissipates the energy. This dissipation of 
energy is known as eddy current loss. Here, in the reported process as MWCNTs are used as high electrical conductivity material therefore decrease in permeability at high frequency is observed due to eddy current loss.

The value of complex permittivity including both real and imaginary part of advanced ARMC shielding material is shown in Table 3 . The value shows the complex permittivity of the sample decreases with the increase in frequency. The dielectric loss may occur due to intrinsic electrical dipole moment with in the shielding material and presence of electromagnetic field due to polarization relaxation (electronic, ionic and orientation). Relatively high permittivity of the sample can cause diectric loss, mainly by dielectric polarization, spontaneous polarization and associated relaxation phenomenon. Due to the presence of MWCNTs having high electrical conductivity 1) the strong polarization, 2) dissipation of electrostatic charges and 3) ohmic losses or multiple scattering caused by the large surface area occurs, this leads to enhanced complex permittivity in the developed advanced ARMC shielding material.

\subsection{EM Wave Absorption Properties of Developed Advanced ARMC Shielding Material}

Reconnoiter of the EM wave absorption properties of the advanced ARMC shielding materials done by using metal plate (being anelectric conductor). A material considering for EM shielding is placed over the limit of 20 Db. The advanced ARMC material with thickness $\mathrm{t}=1.5 \mathrm{~mm}$ showed a minimum R.L of $-35.5 \mathrm{Db}$ at $14.0 \mathrm{GHz}$ with a response band width of $1.8 \mathrm{GHz}$ as shown in Table 4. To obtain more $R$. $L$. value the thickness of the sample can be increased.

The unique designing and ceramic processing of chemical compositions and mineralogical phases of red mud, MWCNTs together with appropriate additive and solvent has been done. It results in the simultaneous and synergistic chemical reactions among various constituents results in the formation of tailored precursor. Further, the ceramic processing of tailored precursor powder in appropriate environment enables in formation of desired multiple ceramic phases namely barium iron titanium silicate (Bafertisite), barium aluminum silicate, iron titanium oxide, barium titanate, Barium iron titanium oxide, barium aluminium oxide, magnetite, iron sulphide (troilite) possessing multi elemental compositions and multi layered crystal structure possessing inherent properties of shielding EMI efficiently.

It is reported in literature that Barium titanate, Barium iron titanium oxides are very good as electromagnetic wave absorber material [25]. Further, in the present process the oxides of titanium and iron present in red mud reacts with barium hydroxide in the presence of alkaline ethylene alcohol leads to the formation of major EMI shielding phase namely barium titanate, Barium iron titanium and alkaline iron oxide species in the matrix of

Table 3. Complex permeability $(\mu)$ and Permittivity $(\varepsilon)$ of advanced ARMC shielding material.

\begin{tabular}{|c|c|c|c|c|c|}
\hline \multirow{2}{*}{ Sr. No. } & \multirow{2}{*}{ Frequency (in GHz) } & \multicolumn{2}{|c|}{ Complex Permeability $(\mu)$} & \multicolumn{2}{|c|}{ Complex Permittivity $(\varepsilon)$} \\
\hline & & Real part & Imaginary part & Real part & Imaginary part \\
\hline 1 & 1 & 0.5 & 0.1 & 4 & 16 \\
\hline 2 & 2 & 0.8 & 0.2 & 3.9 & 14 \\
\hline 3 & 3 & 1 & 0.3 & 3.8 & 13 \\
\hline 4 & 4 & 1.2 & 0.4 & 3.4 & 12 \\
\hline 5 & 5 & 1.3 & 0.4 & 2.8 & 11 \\
\hline 6 & 6 & 1.4 & 0.45 & 2.5 & 8 \\
\hline 7 & 7 & 1.5 & 0.50 & 2.3 & 6.5 \\
\hline 8 & 8 & 1.6 & 0.55 & 2 & 5.8 \\
\hline 9 & 9 & 1.65 & 0.7 & 1.8 & 5.3 \\
\hline 10 & 10 & 1.7 & 0.8 & 1.75 & 5 \\
\hline 11 & 11 & 1.85 & 1.1 & 1.50 & 4 \\
\hline 12 & 12 & 2 & 2.5 & 1.2 & 3 \\
\hline 13 & 13 & 1.3 & 1.8 & 1 & 2.1 \\
\hline
\end{tabular}


Table 4. Reflection loss of advanced ARMC material.

\begin{tabular}{ccc}
\hline Sr. No. & Frequency $(\mathrm{GHz})$ & Reflection loss $(\mathrm{Db})$ \\
\hline 1 & 0 & 0 \\
2 & 2 & 0 \\
3 & 4 & 0 \\
4 & 6 & -1 \\
5 & 8 & -6 \\
6 & 10 & -20 \\
7 & 12 & -30 \\
8 & 14 & -35.5 \\
9 & 16 & -31 \\
\hline
\end{tabular}

in-situ functionalized MWCNTs ranging from micron to sub micron up to nanosize due to the presence of CTAB chosen as one of the surfactant. Further, the multilayer characteristics of bafertisite phase and MWCNTs imparts efficient EMI shielding to the developed advanced ARMC material.

\section{Conclusions}

The following conclusions can be drawn from work carried out for the novel synthesis of advanced ARMC shielding material.

1) The results obtained represent a fundamental starting point for the synthesis of advanced ARMC shielding material utilizing red mud and MWCNTs together.

2) The process enables unique designing of chemical compositions and mineralogical phases of red mud, MWCNTs with appropriate additive and solvent for obtaining in-situ synthesis of advanced EMI shielding material by ceramic processing of tailored precursor.

3) The process involves ceramic processing of tailored precursor for the formation of major EMI shielding phase namely barium titanate, bafertisite phase and alkaline iron oxide species in the matrix of in-situ functionalized MWCNTs as confirmed by XRD studies.

4) The use of CTAB chosen as one of the surfactants enables obtaining particle size of advanced ARMC material raining from micron to sub micron up to nanosize.

5) The FESEM studies revealed that the nanoparticles were almost spherical in shape with particles size in the range of $29-46 \mathrm{~nm}$.

6) The multi layer characteristics of bafertisite phase and MWCNTs impart efficient EMI shielding to the developed ARMC.

7) The electrical conductivity of MWCNTs imparts efficient EMI shielding to the developed ARMC.

8) The presence of $\mathrm{BaTiO}_{3}$ and $\mathrm{TiO}_{2}$ imparts the EMI shielding due to high permittivity and high dielectric constant.

9) The presence of the magnetic phases due to alkaline oxides of iron increases the absorption of EMI waves.

\section{Acknowledgements}

Authors are grateful to Director CSIR-AMPRI Bhopal for providing necessary institutional facilities and encouragement.

\section{References}

[1] Mottahed, B.D. and Manoocheheri, S. (1995) A Review of Research in Materials, Modeling and Simulation, Design Factors, Testing, and Measurements Related to Electromagnetic Interference Shielding. Polymer-Plastics Technology and Engineering, 34, 271-346. http://dx.doi.org/10.1080/03602559508015827

[2] Neelakanta, P.S. and Subramaniam, K. (1992) Controlling the Properties of Electromagnetic Composites. Advanced Materials and Processes, 141, 20-25. 
[3] Lu, G.H., Li, X.T. and Jiang, H.C. (1996) Electrical and Shielding Properties of ABS Resin Filled with Nickel-Coated Carbon Fibers. Composites Science and Technology, 56, 193-200. http://dx.doi.org/10.1016/0266-3538(95)00143-3

[4] Kaynak, A., Polat, A. and Yilmazer, U. (1996) Some Microwave and Mechanical Properties of Carbon Fiber-Polypropylene and Carbon Black-Polypropylene Composites. Materials Research Bulletin, 31, 1195-1206. http://dx.doi.org/10.1016/0025-5408(96)00124-9

[5] Melvin, G.J.H., Ni, Q.Q. and Natsuki, T. (2014) Electromagnetic Wave Absorption Properties of Barium Titanate/ Carnon Nanotube Hybrid Nanocomposites. Journal of Alloys and Compounds, 615, 84-90. http://dx.doi.org/10.1016/j.jallcom.2014.06.191

[6] Micheli, D., Apollo, C., Passtrre, R. and Marchetti, M. (2010) X-Band Microwave Characterization of Carbon-Based Nanocomposite Material, Absorption Capability Comparison and RAS Design Simulation. Composites Science and Technology, 70, 400-409. http://dx.doi.org/10.1016/j.compscitech.2009.11.015

[7] Qin, F. and Brosseau, C. (2012) Review and Analysis of Microwave Absorption in Polymer Composite Filled with Carbonaceous Particles. Journal of Applied Physics, 111, 061301. http://dx.doi.org/10.1063/1.3688435

[8] Huo, J., Wang, L. and Yu, H.J. (2009) Polymeric Nanocomposites for electromagnetic Wave Absorption. Journal of Materials Science, 44, 3917-3927. http://dx.doi.org/10.1007/s10853-009-3561-1

[9] Melvin, G.J.H., Ni, Q.Q., Suzuki, Y. and Natsuki, T. (2014) Microwave-Absorbing Properties of Silver Nanoparticles/ Carnon Nanotube Hybrid Nanocomposites. Journal of Materials Science, 49, 5199-5207. http://dx.doi.org/10.1007/s10853-014-8229-9

[10] Irwin, P., Tan, D.Q. and Cao, Y. (2010) Electromagnetic Interference Shielding Polymer Composites and Methods of Manufacture. US 7815820 B2.

[11] Iyer, V.R., Ungvichian, V. and Neelakanta, P.S. (1993) A Titanium-Dioxide Based Ceramic Composite Dispersed with Conducting Inclusions as an EMI Shielding Material. 1993 IEEE International Symposium on Electromagnetic Compatibility, Dallas, 9-13 August 1993, 168-169. http://dx.doi.org/10.1109/ISEMC.1993.473756

[12] Azadmanjiri, J., Hojati-Talem, P., Simon, G.P., Suzuki, K. and Selomulya, C. (2011) Synthesis and Electromagnetic Interference Shielding Properties of Iron Oxide/Polypyrrole Nanocomposites. Polymer Engineering \& Science, 51, 247-253. http://dx.doi.org/10.1002/pen.21813

[13] Ding, Z.G., Shi, S.Q., Zhang, H.L. and Cai, L.P. (2015) Electromagnetic Shielding Properties of Iron Oxide Impregnated Kenaf Bast Fiberboard. Composites Part B: Engineering, 78, 266-271.

[14] Yang, J. (2006) Research on Comprehensive Utilization of Red Mud from Alumina Plant. M.S. Thesis, Huazhong University of Science and Technology, Wuhan.

[15] Che, R.C., Peng, L.M., Duan, X.F., Chen, Q. and Liang, X.L. (2004) Microwave Absorption Enhancement and Complex Permittivity and Permeability of Fe Encapsulated within Carbon Nanotubes. Advanced Materials, 16, 401-405. http://dx.doi.org/10.1002/adma.200306460

[16] Kim, H.M., Kim, K., Lee, C.Y., Joo, J., Cho, S.J., Yoon, H.S., et al. (2004) Electrical Conductivity and Electromagnetic Interference Shielding of Multiwalled Carbon Nanotube Composites Containing Fe Catalyst. Applied Physics Letters, 84, 589-591. http://dx.doi.org/10.1063/1.1641167

[17] Xiang, C.S., Pan, Y.B., Liu, X.J., Sun, X.W., Shi, X.M. and Guo, J.K. (2005) Microwave Attenuation of Multiwalled Carbon Nanotube-Fused Silica Composites. Applied Physics Letters, 87, 123103. http://dx.doi.org/10.1063/1.2051806

[18] Yang, Y.L. and Gupta, M.C. (2005) Novel Carbon Nanotube-Polystyrene Foam Composites for Electromagnetic Interference Shielding. Nano Letters, 5, 2131-2134. http://dx.doi.org/10.1021/nl051375r

[19] Huang, Y., Li, N., Ma, Y.F., Du, F., Li, F.F., He, X.B., Lin, X., Gao, H.J. and Chen, Y.S. (2007) The Influence of Single-Walled Carbon Nanotube Structure on the Electromagnetic Interference Shielding Efficiency of Its Epoxy Composites. Carbon, 45, 1614-1621. http://dx.doi.org/10.1016/j.carbon.2007.04.016

[20] Verma, S. and Amritphalae, S.S. (2015) A Novel Process for Preparation of Hybrid Nanosized Neodymium Oxybromide and Neodymium Oxide. Russian Journal of General Chemistry, 85, 1528-1531. http://dx.doi.org/10.1134/S1070363215060286

[21] Chen, W., Mai, L.Q., Qi, Y.Y. and Dai, Y. (2006) One-Dimensional Nanomaterials of Vanadium and Molybdenum Oxides. Journal of Physics and Chemistry of Solids, 67, 896-902. http://dx.doi.org/10.1016/j.jpcs.2006.01.074

[22] (1984) Powder Diffraction File, Alphabetical Index Inorganic Phases. Published by JCPDS International Centre for Diffraction Data 1601, Park Lane Swarthmore, Pennsylvania.

[23] Rahman, M.N. (2003) Ceramic Processing and Sintering. CRC Press, Taylor and Francis Group, London.

[24] Zhang, M.-S., Yin, Z., Chen, Q., Zhang, W.F. and Chen, W.C. (2001) Study of Structural and Photoluminescence Properties in Barium Titanate Nanocrystals Synthesis by Hydrothermal Process. Solid State Communications, 119, 
659-663.

[25] Sukanta, D., Nayak, G.C., Sahu, S.K., Routray, P.C., Roy, A.K. and Baskey, H. (2014) Microwave Absorption Properties of Double-Layer RADAR Absorbing Materials Based on Doped Barium Hexaferrite/ $\mathrm{TiO}_{2} /$ Conducting Carbon Black. Journal of Engineering, 2014, Article ID: 468313. 